\title{
Subcostal Transversus Abdominis Plane Block for Postoperative Analgesia
}

\author{
Kai LI ${ }^{1}$, Rui-zhu LIU ${ }^{1}$, Lu CHEN ${ }^{1}$, Guo-qing ZHAO $^{1}$ and Rang-juan \\ $\mathrm{CAO}^{2 *}$
}

${ }^{1}$ Anesthesiology department of China-Japan union hospital of Jilin university , 126th Xian-Tai avenue , Changchun city, Jilin province, P.R.CHINA,130021

${ }^{2}$ Handsurgery department of China-Japan union hospital of Jilin university , 126th Xian-Tai avenue, Changchun city, Jilin province, P.R.CHINA,130021

*corresponding author: Rangjuan Cao:124777681@qq.com 13596195176

Keywords: Transversus abdominis plane, Nerve block, Gastric cancer, Postoperative analgesia

\begin{abstract}
To evaluate the effect of subcostal transversus abdominis plane (TAP) block on postoperative analgesia and short-term prognosis. Forty patients were divided into $\mathrm{T}$ and $\mathrm{N}$ groups. Ultrasound-guided bilateral subcostal TAP block was performed by injection of ropivacaine or normal saline using patient-controlled intravenous analgesia pump. Postoperative hypoalgesia plane was T6-T10 in T group. Postoperative time to press PCIA pump time was (175.85 \pm 8.99$) \mathrm{min}$ and (64.10 \pm 27.37 ) $\mathrm{min}$ in $\mathrm{N}$ group. Sufentanil consumption at postoperative $0-12 \mathrm{~h}$ and 12-24 $\mathrm{h}$ and total sufentanil consumption were significantly lower than $\mathrm{N}$ group. Patients had significantly higher degree of satisfaction than $\mathrm{N}$ group. Off-bed time was $(30.28 \pm 2.01) \mathrm{h}$ and $(39.55 \pm 2.56) \mathrm{h}$ and the first flatus time was $(48.95 \pm 3.83) \mathrm{h}$ and $(64.40 \pm 4.58) \mathrm{h}$ in $\mathrm{N}$ group. It can offer $6 \mathrm{~h}$ analgesia time, enhance analgesic effect within postoperative $24 \mathrm{~h}$, decrease the dosage of opiod drugs and promote intestinal tract function and mobility of recovery.
\end{abstract}

\section{Introduction}

For patients undergoing open radical gastrectomy, the analgesic effect of single intravenous injection was poor. acute upper abdomen pain after surgery severely reduced the comfortableness and affected respiration, off-bed time and the first flatus time and even progressed into neuropathic pain. In 2001, Rafi et al proposed the concept of transversus abdominis plane (TAP) block based upon dissection knowledge, which has been widely applied in the analgesia of lower abdominal operation[1]. Hebbard et al suggested that subcostal TAP was efficacious for upper abdominal operation[2]. Our preliminary experiment validated the good compound analgesic effect of subcostal TAP during surgery[3]. However, whether subcostal TAP could effectively supplement the postoperative intravenous analgesia and affect the quality of postoperative recovery remain unstudied, which is the starting point of this study. 


\section{Materials and Methods}

\section{General Data}

The experimental procedures were approved by Ethical Research Committee in our hospital. Forty patients with I to II grade ASA undergoing open radical gastrectomy between July 2013 and December 2013 were enrolled in this study, aged between 42 and 75 years, weighed 48 to $75 \mathrm{~kg}$. All participants were randomly assigned into transversus abdominis plane group ( $\mathrm{T}$ group; $\mathrm{n}=20$ ) and general anesthesia group ( $\mathrm{N}$ group; $n=20$ ). Patients with allergy to topical anaesthesia drugs, abdominal trauma, mental abnormality, abnormal coagulation, communication disorders and difficulty in puncture were excluded from this clinical trial. All surgical procedures were completed by one single surgeon. Prior to operation, all patients had normal abdominal wall. They were informed about the analgesia strategy and the use of analgesia pump. Informed consents were obtained from all participants and their relatives.

\section{Methods}

Induction and Maintenance of General Anesthesia. After entry into operation room, patients' peripheral vein was cut open, ECG, blood pressure, carbon dioxide of the expiration tip and pulse oxygen saturation were measured. Conventional anesthesia induction was conducted by $0.02 \mathrm{mg} / \mathrm{kg}$ midazolam, $0.6 \mathrm{mg} / \mathrm{kg}$ rocuronium, $0.3 \mu \mathrm{g} / \mathrm{kg}$ sufentanil and $2.0 \mathrm{mg} / \mathrm{kg}$ propofol.

Mechanical ventilation was performed after tracheal intubation at a tidal volume ranging from 6 to $8 \mathrm{ml} / \mathrm{kg}$. Intraoperatively, MAC was maintained between 1.2 and 1.5 by inhalation of sevoflurane, BIS value 45-60 and $\mathrm{P}_{\mathrm{ET}} \mathrm{CO} 235-45 \mathrm{mmHg}$. Intraoperatively, analgesia and vascular active drugs were supplemented based on actual situations, rocuronium was intermittently added. The addition of analgesia agents was discontinued at $1 \mathrm{~h}$ before the conclusion of surgery. Postoperatively, patients were transferred into the post-anesthesia care unit.

Emergence from Anesthesia and Implementation of Postoperative Analgesia .After transferring to the post-anesthesia care unit, patients received mechanical ventilation to maintain the status of anesthesia. The number was randomly assigned automatically by computers. The drugs, including $60 \mathrm{ml}$ of $0.333 \%$ ropivacaine ( $\mathrm{T}$ group) or equivalent amount of normal saline ( $\mathrm{N}$ group), were prepared by the assistants who were not involved with the operation Ultrasound-guided subcostal transversus abdominis plane block was performed (Sonosite M-Turbo, probe 5-10 MHz), making the medication fully form continuous low intensity plane between internal abdominal oblique muscle and transversus abdominis. After the block, the process of emergence from anesthesia was initiated.

After leaving post-anesthesia care unit, patients were connected with disposable patient-controlled intravenous analgesia pump containing $3 \mu \mathrm{g} / \mathrm{kg}$ fentanyl and the maximal use time was $48 \mathrm{~h}$. 


\section{Data Record}

Postoperative evaluation was conducted by one doctor who was blind to this study. The data recorded included: (1) The pain sensation of abdominal wall at postoperative $1,2,4,6,12$ and $24 \mathrm{~h}$ was measured by blunt needle methods. (2) Postoperative time to press patient-controlled intravenous analgesia pump and consumption of fentanyl at different time intervals. (3) The level of sedation was assessed by Ramsay grading: 1 point denotes irritation and anxiety; 2 points means good directional force and quiet cooperation; 3 points denotes drowziness but can deliver correct instructions; 4 points represents sleep status but awakenable; 5 points denotes poor response to awakening; 6 points means deep sleep status and no reaction to awakening. The range of 2 to 4 points was defined as satisfactory sedation and 5-6 points as excessive sedation. (4) The first flatus time postoperatively was utilized to calculate the time of intestinal recovery. (5) Off-bed time (6) Patients' overall degree of satisfaction to analgesia plan was recorded after analgesia treatment (expressed as a scale of 0-100). (7) The incidence of nausea, vomiting, respiratory depression and alternative adverse events were observed and recorded and effective treatment was delivered in a timely manner.

\section{Statistical Analysis}

SPSS 19.0 statistical software package was utilized for data analysis. Normally distributed measurement data were expressed as means \pm standard deviation. Nonnormally distributed measurement data were denoted as the median (quartile). Measurement data were statistically analyzed by t-test. Enumeration data were assessed by chi-square test. $\mathrm{P}<0.05$ was considered as statistical significance.

\section{Result}

\section{General Situation}

All 40 patients successfully underwent puncture. Postoperative observation and management of pain sensation was conducted smoothly. The age, weight and operation time did not significantly differ between two groups, as illustrated in Table 1 .

Table 1 Comparison of general data in patients between two groups

\begin{tabular}{ccc}
\hline Study group & N group & T group \\
Age (year) & $58.55 \pm 5.14$ & $59.10 \pm 6.93 \mathrm{a}$ \\
Weight $(\mathrm{kg})$ & $66.05 \pm 4.06$ & $65.05 \pm 3.37 \mathrm{a}$ \\
Operation time(min) & $163.80 \pm 9.05$ & $162.85 \pm 9.33 \mathrm{a}$ \\
\hline $\mathrm{aP}>0.05$ denotes compared with $\mathrm{N}$ group &
\end{tabular}


The Results Revealed that Patients in the N Group Had No Abnormality in Pain Sensation of Abdominal Wall.

The pain sensation plane in the $\mathrm{T}$ group: the mean plane representing alleviation or loss of pain sensation within postoperative $1 \mathrm{~h}$ reached T6.05, T7.10 at $2 \mathrm{~h}, \mathrm{~T} 8.10$ at 4 $\mathrm{h}$ and T9.75 at $6 \mathrm{~h}$. In the T group, merely 7 patients had slight numbness in abdominal wall at postoperative $12 \mathrm{~h}$, and showed no alleviation or loss of pain sensation compared with alternative sites and organs. The pain sensation of abdominal wall in all patients fully recovered at postoperative $24 \mathrm{~h}$, as shown in Table 2.

Table 2 The plane of pain sensation loss within postoperative $6 \mathrm{~h}$ in the T group

\begin{tabular}{ccccc}
\hline Time & $1 \mathrm{~h}$ & $2 \mathrm{~h}$ & $4 \mathrm{~h}$ & $6 \mathrm{~h}$ \\
& & & & \\
Plane & $6.05 \pm 0.58$ & $7.10 \pm 0.72$ & $8.10 \pm 0.64$ & $9.75 \pm 0.70$ \\
\hline
\end{tabular}

In the $\mathbf{N}$ group, Postoperative Time to Press Patient-controlled Intravenous Analgesia Pump was $(64.10 \pm 27.37)$ Min, Significantly Earlier than $(175.85 \pm 8.99)$ Min in the T Group $(P<0.05)$.

In the $\mathrm{N}$ group, the consumption of fentanyl at postoperative $0-12 \mathrm{~h}$ and $12-24 \mathrm{~h}$ were significantly larger compared with their counterparts in the $\mathrm{T}$ group $(P<0.05)$, whereas no statistical significance was noted at postoperative $24-36 \mathrm{~h}$ and $36-48 \mathrm{~h}$ between two groups in terms of consumption of fentanyl. The total consumption of fentanyl in the $\mathrm{T}$ group was significantly less than that in the $\mathrm{N}$ group, as illustrated in Table 2.

Table 3 Comparison of postoperative fentanyl consumption at different time intervals between two groups $(n=20)$

\begin{tabular}{ccc}
\hline Group & N group & T group \\
$0-12 \mathrm{~h}$ & $53.60 \pm 6.68$ & $27.30 \pm 2.89 \mathrm{~b}$ \\
$12-24 \mathrm{~h}$ & $37.25 \pm 5.42$ & $20.85 \pm 3.54 \mathrm{~b}$ \\
$24-36 \mathrm{~h}$ & $19.45 \pm 2.01$ & $16.30 \pm 1.87 \mathrm{c}$ \\
$36-48 \mathrm{~h}$ & $12.85 \pm 1.60$ & $9.70 \pm 1.30 \mathrm{c}$ \\
& $123.15 \pm 9.35$ & $84.15 \pm 4.44$ \\
\hline Total &
\end{tabular}

Compared with $\mathbf{N}$ Group, the Postoperative Off-bed Time in the T Group was (30.28 \pm 2.01$) ~ h$, Significantly Earlier than $(39.55 \pm 2.56) h(P<0.05)$.

The first flatus time in the $\mathrm{T}$ group was $(48.95 \pm 3.83) \mathrm{h}$ after surgery, significantly earlier than $(64.40 \pm 4.58) \mathrm{h}$ in the $\mathrm{N}$ group $(P<0.05)$. In addition, patients in the $\mathrm{T}$ 
group had significantly higher degree of satisfaction towards postoperative analgesia (88.65 \pm 4.08$)$ compared with their counterparts in the $\mathrm{N}$ group $(77.40 \pm 7.68)$ with a statistical significance. The sedation scores between two groups were within the range of satisfactory sedation ( $2.35 \pm 0.49$ for the $\mathrm{T}$ group and $2.4 \pm 0.8$ for the $\mathrm{N}$ group) with no statistical significance. No statistical significance was observed between two groups regarding the incidence of postoperative nausea, vomiting and other clinical complications, as shown in Table 4.

Table 4 Incidence of adverse events, status of postoperative recovery and patients' degree of satisfaction

\begin{tabular}{ccc}
\hline Group & N group & T group \\
First off-bed time & $39.55 \pm 2.56$ & $30.28 \pm 2.01 \mathrm{~d}$ \\
First flatus time & $64.40 \pm 4.58$ & $48.95 \pm 3.83 \mathrm{~d}$ \\
Degree of satisfaction to & $77.40 \pm 7.68$ & $88.65 \pm 4.08 \mathrm{~d}$ \\
analgesia & $2.25 \pm 0.97$ & $2.35 \pm 0.49 \mathrm{~d}$ \\
Sedation score & $6(30)$ & $3(15)$ \\
Nausea $\mathrm{n}(\%)$ & $2(10)$ & $1(5)$ \\
Vomiting $\mathrm{n}(\%)$ & &
\end{tabular}

$\mathrm{dP}<0.05$ denotes compared with $\mathrm{N}$ group

\section{Discussion}

Ultrasound-guided subcostal transversus abdominis plane block has been widely applied in China. However, the block plane remains debated. Barrington et al demonstrated that single and multiple injections of drugs generated different block planes[4]. Multiple sites of injection could enlarge the spreading scale of medication and block more ganglion segments. Anja Ulrike Mitchel et al adopted ultrasoundguided subcostal transversus abdominis plane block in 20 conscious volunteers and the maximal area of pain sensation block reached T4-L4[5]. In this study, ultrasoundguided subcostal transversus abdominis plane block with injection of $60 \mathrm{ml}$ of $0.333 \%$ ropivacaine at multiple sites. The results revealed that the mean plane of alleviation or loss of pain sensation within postoperative $1 \mathrm{~h}$ was T6.05, T7.10 within $2 \mathrm{~h}, \mathrm{~T} 8.10$ within $4 \mathrm{~h}$, T9.75 within $6 \mathrm{~h}$ and the loss of pain sensation was observed until the $12 \mathrm{~h}$ whereas partial patients felt numbness in abdominal wall. At postoperative $24 \mathrm{~h}$, all patients had normal recovery of abdominal wall. In this experiment, the middle incision was made during open radical gastrectomy from the xiphoid to $2 \mathrm{~cm}$ below umbilicus. Consequently, ultrasound-guided subcostal transversus abdominis plane block can offer $6 \mathrm{~h}$ analgesia time for such incision. McDonnell et al found similar 
findings that the pain sensation of abdominal wall was gradually alleviated within 90 min after block and fully recovered at postoperative $24 \mathrm{~h}[6]$. In recent years, multimode analgesia has been recommended to achieve good analgesia and reduce the adverse events as possible. Subcostal transversus abdominis plane block yields good efficacy with stable block plane and target blocks the sensation nerves on the surface between internal abdominal oblique muscle and internal abdominal oblique muscle, thereby exerting an analgesia effect on abdominal incision. Compared with intravenous and epidural analgesia, it may reduce the incidence of adverse events, such as respiratory depression, urine retention, nausea, vomiting and postoperative intestine blockage, etc. Moreover, it could achieve better analgesia effect. It is supposed that this technique might exert good analgesia effect during upper abdomen surgery, but this hypothesis remains to be further investigated.

The results obtained revealed that postoperative time to press patient-controlled intravenous analgesia pump was $(64.10 \pm 27.37) \mathrm{min}$ in the $\mathrm{N}$ group, significantly earlier than $(175.85 \pm 8.99) \mathrm{min}$ in the $\mathrm{T}$ group, indicating that topical block could achieve relatively good analgesia effect without adjuvant treatment. Moreover, the consumption of sufentanil at postoperative $0-12 \mathrm{~h}$ and $12-24 \mathrm{~h}$ in the $\mathrm{N}$ group was significantly lower compared with those in the T group (both $P<0.05$ ), whereas no statistical significance was noted at postoperative $24-36 \mathrm{~h}$ and $36-48 \mathrm{~h}$ between two groups (both >0.05). These findings suggested that injection of $60 \mathrm{ml}$ of $0.333 \%$ ropivacaine during subcostal transversus abdominis plane block could provide relatively analgesia effect enduring as long as postoperative $24 \mathrm{~h}$, which greatly reduced the required amount of opiod drugs for analgesia purpose postoperatively. Nevertheless, the block effect may sharply vary according to drug, concentration and volume. Previous studies revealed that transversus abdominis plane block could offer at least $48 \mathrm{~h}$ analgesia effect, indicating that albeit it is a safe and reliable block approach, various effects produced by different methods remain to be investigated[7].

The off-bed time in the $\mathrm{T}$ group was $(30.28 \pm 2.01) \mathrm{h}$, significantly earlier than $(39.55 \pm 2.56) \mathrm{h}$ in the $\mathrm{N}$ group $(P<0.05)$.In addition to full analgesia effect, subcostal transversus abdominis plane block also blocks the nerve T6-L1 which dominates the sensation of the frontal abdominal wall. Compared with epidural analgesia, it averts the sensation disorders or movement block of the lower extremity. Pain sensation block of the abdominal wall positively affects postoperative off-bed time and significantly reduces the incidence of postoperative complications, thereby bringing benefits to postoperative recovery and patients' quality of life. Besides, the first flatus time in the $\mathrm{T}$ group was $(48.95 \pm 3.83) \mathrm{h}$ and $(64.40 \pm 4.58) \mathrm{h}$ in the $\mathrm{N}$ group $(P<0.05)$.On one hand, it is a topical block surgery, which causes traumatic stress and inhibits the slow intestinal movement. On the other hand, it can yield relatively good analgesia effect. Thus, the required dosage of intravenous analgesia medication is greatly reduced. In particular, opiod drugs have a systemic effect. A large dose of opiod drugs is likely to lead to enteroparalysis, urine retention and other complications. Consequently, it can accelerate the first flatus time to promote recovery as early as possible. 
The sedation scores in two groups are within the range of satisfactory sedation grade, suggesting that the postoperative analgesia methods adopted between both groups are successful. But, patients in the $\mathrm{T}$ group have a significantly higher degree of satisfaction to postoperative analgesia than their counterparts in the $\mathrm{N}$ group $(P<0.05)$, indicating that it is comfortable and highly accepted by patients. Moreover, no statistical significance was seen between two groups regarding the incidence of adverse events, probably due to simultaneous delivery of a certain dose of ramosetron combined with postoperative analgesia.

Ultrasound technique has been widely applied in nerve block. In this study, ultrasound-guided bilateral subcostal transversus abdominis plane block is employed to greatly reduce the incidence of potential surgical complications possibly caused by blind puncture[8]. Instead, it can precisely reach the dissection site and explicitly display the continuous plane between internal abdominal oblique muscle and internal abdominal oblique muscle, which ensures the efficacy and accuracy of puncture. At present, novel progress has been achieved regarding the nerve block on abdominal wall in China. Traditional Petie triangle block technique has been merely applied in lower abdomen open surgery[9]. After persistent modification, subcostal nerve block has been utilized in the postoperative analgesia of laparoscope surgery of the upper abdomen ${ }^{[10]}$ and gastric cancer surgery[11]. Sound efficacy has been obtained. However, the block effect of subcostal transversus abdominis plane block has not been investigated in a systemic manner. This study is designed to adopt subcostal transversus abdominis plane block in combination with general aneasthesia in gastric cancer patients undergoing open surgery, evaluate quality of postoperative analgesia and postoperative recovery, and measure the area of postoperative block plane and reduction time. All these findings indicate this technique can enhance quality of postoperative recovery, maintain relatively good analgesia plane within postoperative $6 \mathrm{~h}$, significantly reduce the required dosage of opiod drugs, accelerate the first flatus time, yield no anesthesia-related complications and achieve satisfactory analgesia effect. Consequently, ultrasound-guided bilateral subcostal transversus abdominis plane block is a safe and efficacious method for topical block.

\section{References}

[1] Rafi AN.Abdominal field block:a new approach via the lumbar triangle [J]. Anaesthesia, 2001, 56:1024-1026.

[2]Hebbard P.Subcostal transversus abdominis plane block under ultrasound guidance[J]. Anesthesia and Analgesia,2008,106:674-675.

[3]L Yang, K Li, YL Li et al. Application of ultrasound-guide multiple subcostal transversus abdominis plane block in open gastretomy [J].Chinese journal of laboratory diagnosis,2013,17(8):1477-1479.

[4]Barrington MJ, Ivanusic JJ, Rozen WM et al. Spread of injectate after ultrasoundguided subcostal transversus abdominis plane block: a cadaveric study.[J].Anaesthesia, 2009, 64(7): 745- 750. 
[5]Anja UM, Henrik Torup , Egon G Hansen, et al.Effective dermatomal blockade after subcostal transversus abdominis plane block.[J]. Dan Med J, 2012, 59(3): A4404 -4405 .

[6]McDonnell JG, O’Donnell BD, Farrell T, et al. Transversus abdominis plane block: a cadaveric and radiological evaluation. Reg Anesth Pain Med, 2007, 32: 399-404.

[7]O'Donnell BD. The transversus abdominis plane (TAP) block in open retropubic prostatectomy. Reg Anesth Pain Med, 2006, 31:91.

[8]Farooq M, Carey M. A case of liver trauma with a blunt regional anesthesia needle while performing transversus abdominis plane block. Reg Anesth Pain Med,2008, $33: 274-275$.

[9]Carney,J,McDonnell,JG,Ochana,Aet, al.The transversus abdominis plane block provides effective postoperative analgesia in patients undergoing total abdominal hysterectomy[J]. Anesthesia \&amp; Analgesia,2008,107(6):2056-2060.

[10]El Dawlatly AA,Turkistani A,Kettner SC et al.Ultrasound-guided transversus abdominis plane block: description of a new technique and comparison with conventional systemic analgesia during laparoscopic cholecystectomy.[J].British journal of anaesthesia, 2009, 102(6): 763-767.

[11]YQ Wu, ZS Jin, QM Liu, et al. Comparison of degree of pain in patients after radical gastrectomy under different anesthetic regimens [J].Chinese Journal of Anesthesiology, 2012, 32(1): 74-77. 